\title{
Liga acadêmica de humanização e a formação profissional em saúde: percepções de
}

\section{ligantes egressos}

\author{
Academic league of humanization and professional training in health: perceptions of egress ligands \\ Liga acadêmica de humanización y formación profesional en salud: percepciones de egresos \\ ligandos
}

Recebido: 30/08/2021 | Revisado: 04/09/2021 | Aceito: 04/09/2021 | Publicado: 06/09/2021

\author{
Mariana Medeiros Souto Oliveira \\ ORCID: https://orcid.org/0000-0001-5143-224X \\ Universidade Federal do Triângulo Mineiro, Brasil \\ E-mail: mazihamso@gmail.com \\ Ana Lúcia de Assis Simões \\ ORCID: https://orcid.org/0000-0002-2771-6733 \\ Universidade Federal do Triângulo Mineiro, Brasil \\ E-mail: assissimoes@yahoo.com.br \\ Divanice Contim \\ ORCID: https://orcid.org/0000-0001-5213-1465 \\ Universidade Federal do Triângulo Mineiro, Brasil \\ E-mail: divanice.contim@uftm.edu.br \\ Bethania Ferreira Goulart \\ ORCID: https://orcid.org/0000-0003-2855-6767 \\ Universidade Federal do Triângulo Mineiro, Brasil \\ E-mail: bethaniagoulart@yahoo.com.br \\ Mariana Torreglosa Ruiz \\ ORCID: https://orcid.org/0000-0002-5199-7328 \\ Universidade Federal do Triângulo Mineiro, Brasil \\ E-mail: mariana.ruiz@uftm.edu.br
}

\begin{abstract}
Resumo
Objetivo: conhecer o significado da participação em uma liga acadêmica de humanização para a formação profissional em saúde, na perspectiva de ligantes egressos graduados. Metodologia: estudo com abordagem qualitativa, utilizando o Discurso do Sujeito Coletivo, cujos dados foram obtidos por meio de entrevista semiestruturada. Resultados: participaram do estudo, 20 egressos que atuaram como participantes da liga no ano de 2015 (seis psicólogos; quatro enfermeiros; quatro fisioterapeutas; dois nutricionistas; dois biomédicos; um terapeuta ocupacional e um médico) e, 90\% estavam atuando como profissionais da área da saúde no momento da entrevista. Foram extraídas quatro ideias centrais: a liga de humanização possibilitou formação profissional mais humanizada; a liga de humanização contribuiu para valorização das relações interpessoais no cuidado em saúde; a liga de humanização ensinou princípios humanitários como elementos do cuidado em saúde e, a liga de humanização destacou atuação profissional coletiva e respeitosa. Conclusão: Evidenciou-se que a experiência, na liga, impactou na formação profissional, com potencial transformador para um olhar humanístico e cuidado ampliado do usuário, assim como possibilitou que os processos de trabalho em saúde se fundamentem em atuação mais acolhedora, atentiva e sensível.
\end{abstract}

Palavras-chave: Humanização da assistência; Empatia; Hospital clowns; Capacitação de recursos humanos em saúde; Extensão comunitária; Ensino superior.

\begin{abstract}
Objective: to know the meaning of participation in an academic humanization league for professional training in health, from the perspective of egress ligands. Methodology: study with a qualitative approach, using the Collective Subject Discourse, whose data were obtained through semi-structured interviews. Results: 20 egress ligands in 2015 participated in the study (six psychologists; four nurses; four physiotherapists; two nutritionists; two biomedical doctors; one occupational therapist and one doctor) and $90 \%$ were working as professionals at health area at the time of the interview. Four central ideas were extracted: the humanization league allowed for more humanized professional training; the humanization league contributed to the enhancement of interpersonal relationships in health care; the humanization league taught humanitarian principles as elements of health care, and the humanization league highlighted collective and respectful professional performance. Conclusion: It was evident that the experience in the league impacted professional training, with transformative potential for a humanistic look and expanded care for the user, as well as enabling the work processes in health to be based on a more welcoming, attentive and sensitive performance.
\end{abstract}


Keywords: Humanization of assistance; Empathy; Hospital clowns; Health human resource training; Communityinstitutional relations; Education, higher.

\begin{abstract}
Resumen
Objetivo: conocer el significado de la participación en una liga de humanización académica para la formación profesional en salud en la perspectiva de los egresos ligandos. Metodología: estudio con enfoque cualitativo, utilizando el Discurso Colectivo del Sujeto, cuyos datos se obtuvieron a través de entrevistas semiestructuradas. Resultados: participaron del estudio 20 egresos ligandos que actuaron como participantes de la liga en 2015 (seis psicólogos; cuatro enfermeras; cuatro fisioterapeutas; dos nutricionistas; dos médicos biomédicos; un terapeuta ocupacional y un médico) y el $90 \%$ se desempeñaba como profesionales del área de salud en el momento de la entrevista. Se extrajeron cuatro ideas centrales: la liga de humanización permitió una formación profesional más humanizada; la liga de humanización contribuyó a la mejora de las relaciones interpersonales en el cuidado de la salud; la liga de humanización enseñó principios humanitarios como elementos del cuidado de la salud, y la liga de humanización destacó el desempeño profesional colectivo y respetuoso. Conclusión: Se evidenció que la experiencia en la liga impactó la formación profesional, con potencial transformador para una mirada humanista y atención ampliada al usuario, además de posibilitar que los procesos de trabajo en salud se basen en un desempeño más acogedor, atento y sensible.
\end{abstract}

Palabras clave: Humanización de la atención; Empatía; Hospital clowns; Capacitación de recursos humanos en salud; Relaciones Comunidad-institución; Educación superior.

\title{
1. Introdução
}

Em 2003, o Ministério da Saúde implantou a Política Nacional de Humanização (PNH), visando atender às demandas subjetivas manifestadas pelos usuários, profissionais e gestores e promover uma nova cultura de assistência à saúde (Silva, Conceição \& Chagas, 2017). A PNH foi construída como uma nova forma de fazer e pensar práticas de gestão e cuidado. E, nesse sentido, cria estratégias e métodos que buscam fortalecer, reorganizar e aprimorar os processos de trabalho partindo do protagonismo de todos os sujeitos envolvidos na produção de saúde para superar os desafios impostos na prática (Brasil, 2013).

A implementação das estratégias de humanização preconizadas pela PNH na prática ainda é um desafio para profissionais e gestores. Isso porque, esse processo envolve diversos aspectos, como a valorização dos trabalhadores, a interação das profissões na realização do cuidado e a visão holística do indivíduo que busca a assistência. Nesse sentido, o modelo de atenção biopsicossocial viabilizaria o alcance dos objetivos da PNH. Entretanto, gestores e profissionais revelam-se distantes do referido modelo, reproduzindo, no cotidiano, o modelo biomédico (Brasil, 2013). Assim, um dos desafios propostos pela referida política é atuar na formação profissional e romper com a valorização de aspectos técnicos em detrimento de características pessoais que possibilitam bom relacionamento com o usuário, equipe multiprofissional e gestão (Almeida \& Barbosa, 2019).

Neste sentido, a formação profissional revela-se fundamental. Grupos de humanização dentro de faculdades/universidades, que utilizam o lúdico como ferramenta, emergem para preencher lacunas que ainda se fazem presentes no currículo dos profissionais da saúde a respeito do processo de humanização (Nehmy, Mota, Gonçalves, Gontijo \& Guimarães, 2009). A participação de acadêmicos nestes grupos, auxilia no desenvolvimento profissional focado no cuidado holístico e integral do usuário, além de preparar tais profissionais para promover gestão qualificada e eficiente em relação às diretrizes e propostas preconizadas pela PNH (Nehmy et al., 2009; Almeida \& Barbosa, 2019). Além disso, verifica-se que as atividades desses grupos incentivam o estreitamento de laços entre os acadêmicos e os usuários, e assim, viabilizam o aprimoramento de habilidades importantes para o exercício de um profissional humanizado, como comunicação e escuta efetiva, empatia, criatividade e resolutividade (Helmo \& Simões, 2010; Silva, Conceição \& Chagas, 2017).

Nessa perspectiva, em 2004 foi criado o Grupo de Humanização Sarakura, projeto de extensão de uma universidade federal do interior de Minas Gerais, com o intuito de proporcionar aos estudantes da área de saúde experiências lúdicas no contexto hospitalar. Esse projeto foi a base para a criação, no ano de 2006, da Liga Acadêmica de Humanização Sarakura, a qual visava ampliação de conhecimentos sobre humanização, capacitação para o trabalho lúdico hospitalar, com a utilização do 
clown e, espaço para o debate e reflexão da PNH (Helmo \& Simões, 2010). São proporcionados aos ligantes, conhecimentos e vivências que não se encontram em livros ou manuais, cujo foco é a valorização do bom relacionamento entre profissionais e usuários/família como elementos essenciais nas práticas em saúde (Helmo \& Simões, 2010).

Pertinente salientar que as Ligas Acadêmicas, formadas por meio de grupos estudantis, viabilizam aprofundamento de conhecimentos em determinada área (Almeida \& Barbosa, 2019). Não há um conceito único e totalmente claro do que são as ligas, contudo constatam-se diversas definições, assim como uma variedade de objetivos e funções, estabelecidos e relacionados a estas (Nehmy et al., 2009).

Decorridos mais de 15 anos da instituição da PNH e da criação do grupo de humanização Sarakura, a realização deste estudo justifica-se pela possibilidade de atualizar e aprofundar a literatura científica sobre a implementação dos princípios e diretrizes da referida Política nos processos formativos, bem como sobre a atuação de grupos de humanização nas instituições de saúde. Ademais, justifica-se pela necessidade de desvelar a real contribuição destas atividades científico-extensionistas na formação dos estudantes e futuros profissionais em saúde, assim como, pela escassez de estudos sobre a temática específica no cenário em foco na pesquisa.

Diante do exposto, emergiu a seguinte questão norteadora: Qual o significado da participação em uma liga acadêmica de humanização, para a formação profissional em saúde, na perspectiva de egressos graduados?

Desta forma, este estudo teve por objetivo, conhecer o significado da participação em uma liga acadêmica de humanização para a formação profissional em saúde, na perspectiva de ligantes egressos graduados.

\section{Metodologia}

Trata-se de estudo exploratório, com abordagem qualitativa, seguindo-se os critérios do Consolidated criteria for reporting qualitative research (COREQ). O instrumento COREQ conta com três domínios: equipe de pesquisa e reflexividade, desenho do estudo e análise/resultados. Objetiva direcionar aspectos importantes da pesquisa, primando pela confiabilidade. A abordagem supracitada possibilita compreender as situações por meio de comportamentos empíricos, apreendendo a essência do objeto investigado, não dependendo da frequência de aparição, mas sim da sua relevância (Tong, Sainsbury \& Craig, 2007).

Como referencial teórico, adotou-se a PNH (Brasil, 2013) política que contempla princípios e propostas para o trabalho em saúde, com ênfase no fazer coletivo, compartilhado e no cuidado ampliado e complexo sobre o usuário. A PNH viabilizou o diálogo entre os achados do estudo quanto à participação em uma liga acadêmica de humanização, para a formação profissional em saúde, na perspectiva de egressos graduados e a produção teórica.

O presente estudo foi desenvolvido junto a uma liga de humanização de uma universidade federal, localizada no interior do estado de Minas Gerais-Brasil. A referida liga, composta por estudantes de cursos de graduação da área da saúde, comporta turmas anuais com 30 participantes selecionados por meio de processo seletivo, realizado após simpósio formativo. A coordenação é representada por membros discentes, que participaram do projeto anteriormente e docentes colaboradores. São desenvolvidas atividades teóricas e práticas sobre humanização, durante o processo de construção do clown e, após a criação e integração, são realizadas práticas no hospital de ensino vinculado à referida universidade, instituições de longa permanência de idosos e creches.

A população deste estudo foi constituída por estudantes da área da saúde, que fizeram parte da turma de ligantes de 2015. Ressalta-se que a escolha pelo ano de 2015 ocorreu para que, no ato da coleta de dados, os participantes já tivessem concluído a graduação. Para a coleta de dados, a seleção dos participantes foi por conveniência. Foram incluídos egressos graduados que participaram da liga no ano de 2015 como ligante ou coordenador discente do projeto e excluídos graduandos que não estiveram por, no mínimo, um ano na condição de ligante ou que não haviam concluído a graduação. 
Participaram da liga no ano de 2015, 34 estudantes. Todos foram convidados a participar, entretanto, dois ainda não haviam concluído a graduação; um não vivenciou a liga pelo período de um ano; não atendendo, assim, ao critério de inclusão no estudo. Ainda, dois recusaram participar da pesquisa e com nove ligantes não foi possível contato, uma vez que os mesmos não responderam o formulário, após três tentativas (via e-mail e mensagem telefônica). Desta forma, foram entrevistados 20 ligantes, que compuseram a população do estudo.

A coleta de dados ocorreu de outubro de 2020 a fevereiro de 2021, utilizando-se entrevista semiestruturada, realizada por uma graduanda de Enfermagem, a qual foi treinada e calibrada por docentes pela equipe da pesquisa. A entrevista foi guiada por um roteiro, elaborado pelas próprias pesquisadoras, o qual foi submetido à validação aparente e de conteúdo por 11 doutores na temática e/ou na metodologia de pesquisa adotada. O roteiro era dividido em duas etapas. A primeira contemplava os dados sociodemográficos: idade, estado civil, procedência e, dados profissionais: curso de graduação no qual se formou, tempo de participação na liga, atuação na área de formação, local de atuação e tempo de formação. A segunda etapa reunia as questões abertas sobre os significados e percepções de sua vivência na liga para a formação profissional.

Os participantes foram convidados a compor o estudo por meio do endereço eletrônico (e-mail) pela pesquisadora. Após o aceite, o participante respondeu a um formulário do Google Forms ${ }^{\circledR}$, no qual relatou a sua disponibilidade (data e horário) para participar da coleta dos dados, assim como recebeu esclarecimentos sobre os objetivos do estudo. Após o agendamento da entrevista, foi encaminhado ao participante o Termo de Consentimento Livre Esclarecido -TCLE, via formulário Google Forms ${ }^{\circledR}$. Caso optasse por desistir da participação, o mesmo poderia assinalar a alternativa 1 não consinto e, encerrava-se sua contribuição. Caso mantivesse seu posicionamento, ao assinalar a alternativa 2, consinto a participação, era confirmada sua entrevista com a pesquisadora.

As entrevistas foram realizadas por meio da plataforma Google Meet ${ }^{\circledR}$, conforme data e horário, compatíveis para entrevistadora e entrevistado. O link para acesso foi gerado pela pesquisadora e enviado, ao entrevistado, com antecedência de 15 minutos da reunião previamente agendada. Realizou-se a coleta de dados on-line devido à excepcionalidade do momento histórico, considerando a necessidade de acolhida dos participantes e a alteração das rotinas de trabalho provocadas pela pandemia da COVID-19. A duração média das entrevistas foi de 30 minutos. Os depoimentos foram gravados e armazenados pela própria plataforma e transcritos na íntegra, pela própria entrevistadora, para suceder o processo de tratamento do material coletado.

Para a análise e o tratamento dos dados, utilizou-se o Discurso do Sujeito Coletivo (DSC) (Lefreve \& Lefreve, 2012) que, trata-se de um agrupamento em forma de falas únicas, que tenham significados semelhantes no tempo verbal da primeira pessoa do singular, recriando discursos-sínteses com fragmentos de falas, os quais representam a fala de todos os sujeitos. Seu uso nas pesquisas qualitativas permite revelar pensamentos, representações, valores e crenças a respeito de um determinado tema, utilizando métodos científicos (Oliveira et al., 2018).

Foram identificadas as figuras metodológicas que compõem o DSC: 1) Expressões Chave (ECH): trechos fiéis dos depoimentos que contêm as representações da fala do discurso destacados pelo pesquisador, 2) Ideias Centrais (IC): trata-se da apresentação minuciosa dos significados presentes em cada uma das respostas analisadas; e 3) Discursos do Sujeito Coletivo (DSC): que é o agrupamento de expressões-chave presentes nos depoimentos que possuem ideias centrais equivalentes ou complementares, demonstrado nos depoimentos dos sujeitos da pesquisa (Oliveira et al., 2018).

Posteriormente, foram agrupadas as ICs semelhantes e, para cada agrupamento, foram construídos, com as ECH, discursos-síntese na primeira pessoa do singular, nos quais a fala do grupo apareceu como um discurso individual, o DSC. Da análise dos depoimentos, surgiram quatro DSCs, identificados como DSC1, DSC2, DSC3 e DSC4. Os dados sociodemográficos dos participantes foram tratados por meio de estatística descritiva, tais como, frequência absoluta e porcentagem. 
O projeto atendeu às exigências éticas da Resolução no 466/2012 do Conselho Nacional de Saúde, sendo aprovado pelo Comitê de Ética em Pesquisa da Universidade Federal do Triângulo Mineiro, em 26 de setembro de 2020, sob o parecer número 4.301.392.Os participantes receberam esclarecimentos sobre os objetivos do estudo através de formulário do Google Forms ${ }^{\circledR}$, e consentiram a participação, através de instrumento de Consentimento Livre e Esclarecido, inserido no formulário. Todos os entrevistados assinalaram a opção eletrônica correspondente ao consentimento. Caso optassem por recusar a participação, a seção do formulário se encerrava com agradecimento. Ressalta-se que não foram registradas recusas nesta etapa.

Para preservar o sigilo e a identidade dos participantes, os relatos dos entrevistados foram identificados por códigos. Cada entrevista foi codificada pela letra E, de entrevista e uma sequência numérica, que seguiu a ordem da coleta de dados (E1, E2, E3...).

\section{Resultados}

Participaram do estudo, 20 egressos que atuaram como participantes da liga no ano de 2015. Destes, 17 (85\%) eram do sexo feminino e três (15\%) eram do sexo masculino; a idade variou de 24 a 29, com média de 26,55 $\pm 1,28$ anos e todos eram solteiros. O grupo apresentava distinta formação profissional, sendo constituído por seis psicólogos; quatro enfermeiros; quatro fisioterapeutas; dois nutricionistas; dois biomédicos; um terapeuta ocupacional e um médico.

O tempo de vivência na liga variou de um a quatro anos, com média de 1,85 $\pm 1,04$ anos; 18 (90\%) estavam atuando profissionalmente no momento da entrevista e dois (10\%) ainda não atuavam após a formação, que ocorreu entre um a quatro anos; cinco (25\%) estavam fazendo curso de pós-graduação stricto sensu e um participante (5\%) estava cursando pósgraduação lato sensu. A maioria dos entrevistados era procedente do estado de São Paulo (11 - 55\%), enquanto seis (30\%) eram do próprio município de localização da universidade, dois eram de municípios do estado de Minas Gerais e um era procedente do Distrito Federal.

A partir da análise dos discursos, revelaram-se quatro ideias centrais sobre os significados e percepções a respeito da sua participação/vivência na liga; sendo que $11(55 \%)$ dos entrevistados relataram que a liga impactou para uma formação profissional mais humanizada; seis (30\%) revelaram que a liga de humanização chamou atenção para as relações interpessoais como ferramentas para o cuidado em saúde; e nove (45\%) discorreram que a liga de humanização trouxe à tona os princípios humanitários como elementos da assistência à saúde, nove (45\%) descreveram a liga de humanização como um ensinamento para o trabalho coletivo.

\section{Ideia Central 1: A liga de humanização possibilitou formação profissional mais humanizada}

O discurso coletivo evidenciou que a participação na liga de humanização impactou na formação profissional em saúde, com potencial transformador para o cuidado ampliado e um olhar humanizado sobre o usuário.

DSC1: Participar da liga significou um fator potencializador na minha formação, eu percebi o envolvimento da questão mais humana dentro de um curso que é totalmente focado na técnica. Percebi que aprender sobre humanização foi importante para minha atuação profissional. Foi um diferencial na formação universitária, o aprendizado sobre humanização foi a base para minha atuação no hospital durante a graduação. A liga de humanização foi uma ferramenta de transformação, foi um desafio na graduação, pude olhar para sociedade de uma forma diferente e enxergar cada pessoa como um ser humano, não apenas uma patologia. Aprendi ser mais empático na relação profissional-cliente e ter a percepção sobre uma liga universitária que complementa o que falta no curso de graduação. Significou a superação e amadurecimento sobre minha escolha profissional, foi como uma linha muito 
tênue entre ser preparada para o trabalho em saúde e refletir meu papel enquanto pessoa sobre o sistema de saúde. Significou a aplicação de conceitos teóricos na prática, me proporcionou relacionar as múltiplas oportunidades de realização crescimento pessoal, despertando para o aprimoramento de valores eu acredito. Por ser uma liga multidimensional significou tanta coisa, mas antes de tudo uma oportunidade imensa de crescer enquanto pessoa. (E1, E2, E4, E7, E9, E10, E11, E12, E16, E17, E19)

\section{Ideia Central 2: A liga de humanização contribuiu para valorização das relações interpessoais no cuidado em saúde}

As falas revelaram que a vivência na liga de humanização possibilitou uma atuação profissional mais atentiva e sensível, com destaque para construção de relações interpessoais saudáveis e acolhedoras.

DSC2: Foi muito bom para meu desenvolvimento profissional, a liga marcou muito minha a trajetória, me fez ser uma profissional mais humanizada, percebi que a liga transformou o olhar para o outro principalmente na atuação diária do nosso trabalho. Ela foi importantíssima no relacionamento com paciente que eu atendo, fez a diferença na minha prática sim, principalmente no acolhimento das pessoas que atendo, facilitou o manejo, a escuta, ter sensibilidade. Me fez um profissional mais próximo das pessoas que precisa dos meus cuidados, desenvolver que o cuidado atentivo e humanizado em todos os lugares que eu estiver atuando, seja hospital, no ambulatório, na empresa, eu carrego muito isso para minha atuação profissional. (E3, E5, E8, E11, E15, E20)

\section{Ideia Central 3: A liga de humanização ensinou princípios humanitários como elementos do cuidado em saúde}

As entrevistas demonstraram que a vivência na liga impactou positivamente na visão holística e nas relações do estudante com o paciente, principalmente, o hospitalizado. Trouxe à tona elementos como solidariedade, compaixão e resiliência.

DSC3: Eu lembro da sensação de começar a participar, foi uma das experiências mais positivas, entender sobre voluntariado. Foi muito encantamento, a liga trouxe a solidariedade ideal de cuidado nas primeiras experiências no hospital. Foi um momento surreal e transformador, eu era até um pouco tímida para lidar com pessoas, Foi gratificante por agregar sentimentos saudáveis e positivos como quando entrei no hospital pela primeira vez, das pessoas que eu conheci, de tudo que vivi, foi mágico atender os pacientes, lembrar da emoção de cada momento vivido, você não tem noção como isso foi importante são muitas coisas positivas. Foi uma experiência que vai além de atuar na área da saúde, a questão do cuidado humanizado todo respaldado na Política Nacional de Humanização. Foi uma experiência que vou levar para além na minha formação como pessoa, como ser humano, eu consegui sorrir com os olhos, não vou esquecer, a gente aprendia com os pacientes. Foi experiência da compaixão, da resiliência porque são as histórias pessoais que marcaram minha atuação e uma das melhores oportunidades aqui dentro da universidade a liga Sarakura. (E1, E2, E3, E6, E9, E13, E18, E19, E20)

\section{Ideia Central 4: A liga de humanização destacou atuação profissional coletiva e respeitosa}

A partir dos discursos, nota-se que a liga fundamenta ou norteia a maneira como os egressos realizam o trabalho em saúde. Desta forma, a liga representa uma ferramenta que guia o fazer em saúde e impacta diretamente nos processos de trabalho, na perspectiva coletiva.

DSC4: A liga me proporcionou desenvoltura no ambiente de trabalho, de saber mediar os conflitos, saber o que falar, saber quando falar, sabe? Construído uma postura e como posicionar sobre situações que a gente encontra no nosso 
cotidiano profissional. Ofereceu subsídios para minha conduta profissional. Foi uma experiência muito positiva, que me ajudou a mediar situações práticas do dia-a-dia de trabalho em todos os níveis de atenção à saúde. Hoje eu não conseguiria trabalhar na minha profissão da forma como eu trabalho, como, dosar e respeitar o limite do outro, é indescritivel essa experiência moldou minha vida profissional. Foi na liga que experimentei ter mais confiança e desenvolver habilidades para lidar com outras pessoas, vivenciar a relação profissional, paciente. (E3, E4, E6, E7, E8, E10, E12, E14, E19)

\section{Discussão}

A liga, cenário do estudo, caracteriza-se como uma atividade extensionista de educação interprofissional, a qual envolve duas ou mais profissões com identidade profissional e papéis bem definidos, que aprendem juntos, de modo interativo, com objetivo de melhorar a colaboração no trabalho e garantir um cuidado efetivo, seguro e de alta qualidade, estratégia altamente recomendada pela Organização Mundial de Saúde (Reeves, 2016). Além disso, as ligas são compreendidas como espaço transformador, promovendo vínculos entre estudantes, professores e sociedade, além da possibilidade de aproximação entre cenários diversificados de práticas e diferentes segmentos da população (Silva \& Flores,2015, Cavalcante et al., 2021).

Destaca-se que este é recurso extremamente útil para a formação acadêmica, uma vez que pesquisas indicam que estudantes do curso de graduação ainda no primeiro ano já constroem uma série de estereótipos sobre as demais profissões (Barr, Koppel, Reeves, Hammick \& Freeth, 2005), o que pode se tornar uma barreira/obstáculo para o trabalho efetivo em equipe no futuro, sendo louváveis iniciativas, como a liga apresentada neste estudo.

De acordo com os discursos, a vivência na liga conduziu a uma formação profissional mais humanizada, no contexto do trabalho em saúde. Cenários de atuação na perspectiva desse modelo de liga representam espaços de aprendizado ampliado, que permitem aprofundamento para além da técnica, promovendo construção de interações críticas entre universidade, sociedade e sistema de saúde (Pasche, 2010; Cavalcante et al., 2018). A literatura evidencia a necessidade de iniciativa como esta para o desenvolvimento de práticas reflexivas. Muitos estudantes relacionam ou confundem empatia com humanização e, por não saberem lidar com os próprios sentimentos, têm uma formação fundamentada no currículo baseado em habilidades e técnicas, que não valoriza comportamentos, atitudes e relações. Isto pode reforçar a prática de desumanização profissional, ainda durante sua formação (Beneditto \& Gallian, 2018). As atividades práticas são entendidas, pelos estudantes, como a oportunidade para desenvolver o conceito de humanização e, os docentes são exemplos e agentes do cuidado humanizado (Freitas \& Ferreira, 2016).

Neste sentido, destaca-se que a experiência e a habilidade técnica são importantes para o processo de ensinar, influenciando na segurança do docente e trazendo mais subsídios, significados e realidade à sala de aula. Mas, segundo os mesmos, o ensinar em saúde representa um desafio que ultrapassa o cognitivo e o domínio do conteúdo teórico e das técnicas, que não são suficientes, com necessidade de domínio na área pedagógica (Treviso \& Costa, 2017), que influenciarão não só o trabalho docente mas, a formação destes futuros profissionais.

A vivência na liga de humanização evidenciou que as relações interpessoais são ferramentas para o cuidado em saúde, valorizando uma atuação mais acolhedora, atentiva e sensível, no cotidiano. O cuidado em saúde é complexo, no qual emergem diferentes modos de ver, ouvir, pensar, sentir e cuidar, sendo uma experiência transformadora tanto para o cuidador quanto para a pessoa que é cuidada. Deve ser uma experiência única, não limitada a protocolos, normas, rotinas e regras, com possibilidades de criação a cada encontro e em cada relação construída (Andrade, Givigi \& Abrahão, 2017). Neste sentido, esta aproximação com olhar diferenciado sobre o cuidado, ainda durante a formação, pode influenciar favoravelmente na atuação profissional futura. 
Desta forma, as ligas possibilitam para os estudantes, experiências e vivências potentes para transformação do cenário de práticas de saúde, mediadas por ações de ensino, pesquisa, extensão, contribuindo de forma efetiva na formação profissional (Carvalho e Araújo et al., 2019).

Um dos discursos desvelou que a liga de humanização valoriza os princípios humanitários como ferramentas para o cuidado em saúde. Ressalta-se que o clown é a característica marcante da liga em foco. O clown, ou o palhaço de hospital, se apresenta como um importante complemento assistencial, com utilização de diferentes recursos, na sua atuação/prática, como a música, o malabarismo, a improvisação, a magia, a narração de histórias e uso de fantoches, entre outras atividades, podendo ser aplicado para todos os públicos. O palhaço de hospital baseia-se nos pressupostos de que "rir é o melhor remédio" e do "poder curativo do amor", permitindo aos pacientes, principalmente, hospitalizados, a expressão e fortalecimento emocional (Lopes-Júnior et al., 2020).

A vivência do clown, permite aos adultos que a vivenciam, a possibilidade de serem lúdicos, criativos e flexíveis com suas emoções e sentimentos, lidando melhor com os paradoxos dos processos de trabalho em saúde e com as contradições enfrentadas no cotidiano (Gordon, Shenar \& Pendzikc, 2018). Um estudo com 160 clowns voluntários constatou maiores escores de autoeficiência, otimismo e empatia. A empatia é entendida como uma construção individual muito complexa, não aprendida com técnicas, mas, ao causar reação em outras pessoas, isto possibilita olhar mais para si mesmos e lidar melhor com os sofrimentos cotidianos, quer seja nas suas relações ou nos processos de trabalho (Dionigi, Casu \& Gremigni, 2020), trazendo inúmeros benefícios para quem faz esta construção.

Pertinente ressaltar que o clown contribui para a redução do estresse de profissionais de saúde. Isto significa que ao reduzir o estresse e propiciar melhores condições para os pacientes, consequentemente, os profissionais conseguem vislumbrar benefícios nos seus processos de trabalho (Gomberg, Raviv, Fening \& Meiri, 2020).

Um dos discursos trouxe à tona a liga de humanização como um ensinamento para o trabalho coletivo, contribuindo para o processo de trabalho em saúde. O trabalho em saúde possui particularidades, que o diferencia dos demais trabalhos. Tem natureza complexa, requer conhecimento, apresenta diversidade profissional, múltiplas práticas uni e interprofissionais, possui incorporação dos mais diferentes tipos de tecnologia e necessita ao mesmo tempo de uma organização/gestão única (Montanari, 2018).

A análise das práticas de saúde enquanto trabalho e processo, sustentam-se na concepção do significado social dos indivíduos (Vigotski, 2007), e, entende-se por significados, as relações compreendidas e interpretadas individualmente no mundo social que vivem (Vigotski, 2001). Estudo realizado com profissionais que atuam na assistência primária desvelou significados e percepções atribuídos ao processo de trabalho. Os profissionais demonstraram conhecimento técnico atualizado, mas, no cotidiano, não o aplicam ou realizam atividades contraditórias ao que aprenderam. Segundo eles, este comportamento se dá pelas experiências na formação e também pelas vivências anteriores, encontrando como resposta mais rápida e simples, atividades puramente técnicas e automatizadas, evidenciando, a tensão entre o desejável ou ideal e o instituído, que constitui suas práticas cotidianas (Carrapato, Castanheira \& Placideli, 2018).

Esta confusão entre o que se deseja e o que se faz, deve ser repensada e discutida, pois pode levar ao adoecimento do profissional, que ao considerar estes processos, não implica desconsiderar outros âmbitos e valores de sua vida. Essas ações, consideradas protetoras, automatizadas e contraditórias, muitas vezes são destrutivas para saúde dos indivíduos que vivenciam este conflito cotidiano (Viapiana, Gomes \& Albuquerque, 2018). Assim, ao se identificar elementos da humanização presentes nos processos de trabalho, nota-se a importância desta formação ainda durante a graduação para os indivíduos.

Este estudo apresenta como limitação a sua realização com uma única turma de ligantes egressos. Mas, em contrapartida, aponta-se como potência, o fato de a pesquisa ter sido desenvolvida com a quase totalidade de ligantes do referido ano e que a maioria dos egressos entrevistados estavam inseridos nos contextos do trabalho em saúde. 
Por fim, chama a atenção nos discursos, a importância e o impacto da participação na liga na formação assim como na atuação profissional dos ex-ligantes. As ligas são indiscutivelmente benéficas tanto para o estudante quanto para a comunidade em geral. Possibilitam compartilhamento de saberes adquiridos pelo ligante para a comunidade, proporcionam aprendizados teóricos, práticos e reflexivos, evidenciando sua relevância social e acadêmica, a convergência com a formação em saúde e o compromisso com a essência da extensão universitária (Cavalcante et al., 2018; Viapiana et al., 2018; Cavalcante et al., 2021). Ao desvelar estes aspectos, o estudo avança ao demonstrar o potencial transformador das ligas para os futuros profissionais e processos de trabalho em saúde, mais coletivos e solidários.

\section{Conclusão}

Utilizando-se do DSC, esta investigação possibilitou identificar as percepções e significados da vivência na liga de humanização para a formação profissional em saúde.

Constatou-se, por meio dos discursos, que a experiência na referida liga impactou positivamente na formação profissional em saúde. Contribuiu para um fazer em saúde pautado em postura mais humanizada, acolhedora e solidária. Destacou que tal formação deve transcender aspectos puramente técnicos, mas considerar a complexidade humana, entendendo que a sensibilidade e a escuta ocupam posição de destaque na assistência à saúde.

A liga viabilizou a prática no cotidiano de saúde de elementos como solidariedade, compaixão e resiliência. Desta forma, contribuiu não somente para formação profissional, mas também humana.

Para além do contato profissional de saúde-usuário, a vivência na liga de humanização despertou para o aspecto organizacional dos serviços, destacando a viabilidade do trabalho coletivo para um fazer em saúde mais justo e equânime.

Não se pretende esgotar a temática, mas enfatiza-se que o estudo desvelou a relevância da liga de humanização na formação do profissional de saúde, impactando na assistência, na realização pessoal e profissional e, inclusive, na gestão de serviços de saúde.

Sugere-se a realização de novas pesquisas junto a outras ligas com vistas a dar visibilidade para esta possibilidade na formação em saúde.

\section{Referências}

Almeida, S. M. V. \& Barbosa, L. M. V. (2019). Curricularização da extensão universitária no ensino médico: o encontro das gerações para humanização da formação. Revista Brasileira de Educação Médica, 43 (1). 10.1590/1981-5271v43suplemento1-20190013

Andrade, E. O., Givigi, L. R. P. \& Abrahão, A. L. (2017). A ética e o cuidado em si como criação de possíveis no trabalho em saúde. Interface (Botucatu). $10.1590 / 1807-57622016.0643$

Barr, H., Koppel, I., Reeves, S., Hammick, M. \& Freeth, D. (2005). Effective interprofessional education: argument, assumption and evidence. Oxford: Blackwell.

Beneditto, M. A. C \& Gallian, D. M. C. (2018). Narrativas de estudantes de Medicina e Enfermagem: currículo oculto e desumanização em saúde. Interface (Botucatu), 22 (67). 10.1590/1807-57622017.0218

Brasil. (2013). Ministério da Saúde. Política Nacional de Humanização (PNH).

Carrapato, J. F. L., Castanheira, E. R. L. \& Placideli, N. (2018). Percepções dos profissionais de saúde da atenção primária sobre qualidade nos processos de trabalho. Saúde \& Sociedade, 27 (2). 10.1590/S0104-12902018170012

Carvalho e Araújo, C. R., Lopes, R. E., Dias, M. S. A., Ximenes Neto, F. R. G., Farias, Q. L. T \& Cavalcante, A. S. P. (2019). Contribuição das ligas acadêmicas para formação em enfermagem. Enfermagem em Foco, 10 (6): 137-142.

Cavalcante, A. S. P., Vasconcelos, M. I. O., Ceccim, R. B., Maciel, G. P., Ribeiro, M. A., Henriques, R. L. M., \& da Silva, M. R. F. (2021). Em busca da definição contemporânea de "ligas acadêmicas" baseada na experiência das ciências da saúde. Interface (Botucatu), 25: e190857. 10.1590/interface.190857

Cavalcante, A. S. P., Vasconcelos, M. I. O., Lira, G. V., Henriques, R. L. M., Albuquerque, I. N. M., Maciel, G. P., \& Gomes, D. F. (2018). As ligas acadêmicas na área da saúde: lacunas do conhecimento na produção científica brasileira. Revista Brasileira de Educação Médica, 42(1):199-206. $10.1590 / 1981-52712018 v 42 n 1 R B 20170081$ 
Dionigi, A., Casu, G. \& Gremigni, P. (2020). Associations of self-efficacy, optimism, and empathy with psychological health in healthcare volunteers. International Journal of Environmental Research and Public Health, 2020, 17: 6001. 10.3390/ijerph17166001

Freitas, F. D. S. \& Ferreira, M. A. (2016). Humanization knowledge of undergraduate nursing students. Revista Brasileira de Enfermagem, 69 (2): 261-268. $10.1590 / 0034-7167.2016690211 \mathrm{i}$

Gomberg, J., Raviv, A., Fenig, E. \& Meiri, N. (2020). Saving costs for hospitals through medical clowning: a study of hospital staff perspectives on the impact of the medical clown. Clinical Medicine Insights: Pediatrics, 14: 1-7. 10.1177/1179556520909376

Gordon, J., Shenar, Y. \& Pendzikc, S. (2018). Clown therapy: A drama therapy approach to addiction and beyond. The Arts in Psychotherapy, 57: 88-94 10.1016/j.aip.2017.12.001

Helmo, F. R. \& Simões, A. L. A. (2010). Liga de humanização Sarakura: contribuição para a formação dos profissionais da saúde. Ciência Cuidado e Saúde, 9(1):149-154. 10.4025/cienccuidsaude.v9i1.10564

Lefreve, F. \& Lefreve, A. M. C. (2012). Pesquisa de representação social: um enfoque qualiquantitativo: a metodologia do Discurso do Sujeito Coletivo. 2. ed. Liber Livro.

Lopes-Júnior, L. C., Bomfim, E., Olson, K., Neves, E. T., Silveira, D. S. C., Nunes, M. D. R., \& Lima, R. A. G. (2020). Effectiveness of hospital clowns for symptom management in paediatrics: systematic review of randomised and non-randomised controlled trials. BMJ,371:m4290. 10.1136/bmj.m4290

Montanari, P. M. (2018). Formação para o trabalho no ensino das graduações em saúde. Saúde \& Sociedade, 27 (4). 10.1590/50104-12902018180974

Nehmy, R. M. Q., Mota, J. A. C., Gonçalves, A. J. P., Gontijo, N. P. \& Guimarães, Y. L.(2009). Uma experiência de extensão, iniciação científica e de formação humanista de estudantes de medicina: o projeto Abraçarte. Revista Médica de Minas Gerais, 19(4): S64-S70.

Oliveira, S. X., Oliveira, M. D., Camboim, F. E. F., Nóbrega, M. M. S., Lima, A. B. \& Melo, A. C. (2018). Teorias das representações sociais e o discurso do sujeito coletivo como ferramentas para o desenvolvimento de pesquisas qualitativas. Temas Saúde, (esp): 126-135.

Pasche, D. F. (2010). Humanizar a formação para humanizar o SUS. In: Ministério da Saúde. Caderno humaniza SUS 1. Ministério da Saúde.

Reeves, S. (2016). Porque precisamos da educação interprofissional para o cuidado efetivo e seguro. Interface (Botucatu), 20 (56): 185-196. 10.1590/180757622014.0092

Silva, A. S. \& Flores, O. (2015). Ligas acadêmicas no processo de formação de estudantes. Revista Brasileira de Educação Médica, 39(3):410-425. $10.1590 / 1981-52712015 v 39 n 3 e 02592013$

Silva, C. P. R., Conceição, A. P. \& Chagas A. P. S. (2017). Clown - o palhaço como intervenção e humanização em saúde. Journal of Health and Biological Sciences, 5(4), 352-359.

Tong, A., Sainsbury, P. \& Craig, J. (2007). Consolidated criteria for reporting qualitative research (COREQ): a 32-item checklist for interviews and focus groups. International Journal for Quality in Health Care, 19 (6): 349 -357. 10.1093/intqhc/mzm042

Treviso, P. \& Costa, B. E. P. (2017). Percepção de profissionais da área da saúde sobre a formação em sua atividade docente. Texto \& Contexto Enfermagem, 26 (1):e5020015. 10.1590/0104 07072017005020015

Viapiana, V. N., Gomes, R. M. \& Albuquerque, G. S. C. (2018). Adoecimento psíquico na sociedade contemporânea: notas conceituais da teoria da determinação social no processo de saúde-doença. Saúde Debate, 42(4). 10.1590/0103-110420185414

Vigotski, L. S. (2001). A construção do pensamento e da linguagem. Martins Fontes.

Vigotski, L. S. (2007). A formação social da mente: o desenvolvimento de processos psicológicos superiores. (7a ed.), Martins Fontes. 